\title{
Análise de uma Abordagem Didática Sobre o Papilomavírus Humano (HPV) em um Livro Didático de Ciências da Natureza
}

\section{Analysis of a Teaching Approach about Human Papilomavirus (HPV) in a Natural Science Teaching Book}

\author{
João Matheus Albertoni Macedo ${ }^{\mathrm{a}}$; Crys Michelly de Oliveira Dutra ${ }^{\mathrm{a}}$; Antonio Sales ${ }^{\mathrm{a}}$;Luciana Paes de Andrade*a
}

${ }^{a}$ Universidade Anhanguera Uniderp, Programa de Pós-Graduação Stricto Sensu de Ensino de Ciências e Matemática. MS, Brasil.

*E-mail: luciana.andrade@uniderp.com.br

\begin{abstract}
Resumo
O presente artigo tem como objetivo realizar uma discussão sobre a alfabetização e o letramento científico utilizando os pressupostos de Antoni Zabala em relação à prática educativa na disciplina de Ciências. A pesquisa apresentada é de caráter documental e examina um material aprovado pelo Programa Nacional do Livro e do Material Didático, selecionado pelos professores de uma escola da rede pública estadual para o Ensino Fundamental final, no município de Campo Grande, Mato Grosso do Sul. A análise ocorre a partir da identificação de uma proposta didática apresentada no livro do sétimo ano de Ciências da Natureza, que segue as diretrizes da Base Nacional Comum Curricular que se trata da vacinação contra papilomavírus humano no processo de construção dos conhecimentos conceituais, procedimentais e atitudinais, no âmbito da prevenção e valorização da vida, da saúde e da produção e informação científica. Essa investigação foi realizada durante a disciplina de Linguagens e Alfabetização Científica do Programa de Mestrado em Ensino de Ciências e Matemática. Os resultados evidenciaram que a proposta didática de pesquisa possibilita a construção de conceitos, procedimentos e atitudes, propondo ações de resoluções de problemas na dimensão conceitual, no que se refere à apropriação de conhecimentos científicos, permitindo questionamentos sobre a saúde e atitudes de prevenção no campo atitudinal.
\end{abstract}

Palavras-chave: Conhecimento Científico. Saúde Pública. Alfabetização.

\begin{abstract}
This paper aims to conduct a discussion on literacy and scientific literacy using the assumptions of Zabala (1998) concerning the educational practice in science discipline. This research is documental and examines a material approved by the Brazilian Textbook Program, selected by the teachers of a public school for the final elementary school, in the municipality of Campo Grande, Mato Grosso do Sul state. The analysis is based on the identification of a didactic proposal presented in a Natural Sciences book for the seventh-grade, that follows the National Common Curricular Base guidelines. It approaches the human papillomavirus vaccination and the process of building conceptual, procedural and attitudinal knowledge on the context of prevention and valuation of life, health and safety. This research was carried out during the Languages and Scientific Literacy discipline of the Master's Program in Science and Mathematics Teaching. The results showed that the didactic research proposal allows the construction of concepts, procedures and attitudes, offering problem solving actions, in the conceptual dimension, regarding the scientific knowledge appropriation, also allowing questions about health and prevention attitudes in the attitudinal field.
\end{abstract}

Keywords: Scientific Knowledge, Public Health, Literacy.

\section{Introdução}

O termo "alfabetização" possui semelhança com os termos em inglês literacy e illeteracy, e com os termos em francês alphabétisme e analphabétisme, que significam, respectivamente, alfabetizado e analfabeto. É importante realizar uma comparação dos significados e colocações para os termos "alfabetização" e "letramento". A Organização das Nações Unidas (ONU) sugeriu que o termo "alfabetizado" fosse utilizado para designar as seguintes competências a um indivíduo: realizar leitura de textos e utilizar a escrita para se comunicar. Se um indivíduo consegue realizar a leitura ou redigir um texto, mas não consegue compreender o que foi lido ou escrito, o mesmo será considerado um analfabeto funcional. A França passou a utilizar o termo littérisme para mencionar pessoas que conseguem utilizar a escrita e a leitura para compreender o conteúdo descrito em um texto e propagar a informação interpretada, recebendo o nome de letramento científico no Brasil (TEIXEIRA, 2013).

Ainda, de acordo com Teixeira (2013), os termos "alfabetização científica" e "letramento científico" são utilizados no Brasil para traduzir um termo em inglês, scientific literacy. A princípio, o termo expressava que o conhecimento científico era importante para a sociedade estadunidense, pois a população teria conhecimento sobre questões econômicas do país, gerando um sentimento de bem-estar social entre os cidadãos. Anos depois, o termo scientific literacy foi utilizado para demonstrar como o ensino e o conhecimento em ciências eram importantes para a população, assim como a leitura e a escrita. O termo foi utilizado como um slogan para descrever 
a importância do ensino de Ciências.

De acordo com Sasseron e Carvalho (2011), alfabetização ou letramento científico são definidos como um ensino que possibilita o aluno a compreender conceitos científicos e, posteriormente, desenvolver capacidades e competências que lhes servirão de ferramenta para interpretar informações que estejam no campo da informação científica. Desse modo, a alfabetização ou letramento científico têm o objetivo de educar os indivíduos que compõem a sociedade, para que os mesmos compreendam e saibam fazer o uso correto dos conhecimentos científicos, divulgando-os. Dessa forma, independentemente de como são chamadas, ambas as expressões possuem o mesmo objetivo que é a construção do conhecimento científico que pode ser utilizado em questões ambientais, sociais e de saúde pública.

A divulgação científica deve estar presente em todos os anos do Ensino Básico e para isso é necessário que o professor seja letrado cientificamente. Ele deve ser capaz de ler mais do que o texto explicita, ou seja, ele precisa ir além do domínio da sua área de formação antes de propagar qualquer conhecimento científico. Se o mesmo não compreender os avanços científicos e tecnológicos, e não souber distinguir os tipos de conteúdo presentes no texto, sua relação com a ciência ficará comprometida. É importante a oferta de possibilidades ao estudante para que ele realize a escrita e leitura adequadas dos produtos científicos, e compreenda totalmente a mensagem do texto. Essa é a condição que permite a participação de crianças, adolescentes e jovens em discussões sobre as consequências que um produto da ciência pode trazer à sociedade (MAMEDE; ZIMMERMANN, 2005).

De acordo com Santos (2007), para que ocorra letramento científico nas escolas é necessário que o ensino de Ciências deixe de ser apenas uma disciplina que propaga os acontecimentos científicos sem realizar conexões com as demais áreas de ensino. Esse deve se integrar às outras disciplinas, interligando o resultado das produções científicas com as áreas de estudo. Dessa forma, ao unificar as demais disciplinas ao ensino de Ciências, o professor conseguirá realizar o trabalho de letramento científico com o estudante. $\mathrm{O}$ que se espera do mesmo é que ele não apenas leia e escreva, mas que também contribua para desenvolver a capacidade de interpretação e tomada de decisão na argumentação dos produtos provenientes do avanço científico e tecnológico. Por consequência, ele se torna capaz de criar respostas que poderão solucionar problemas da sociedade.

A Base Nacional Comum Curricular (BNCC) apresenta, em seu texto, na etapa do Ensino Fundamental as disciplinas que integram as Ciências da Natureza e o avanço do letramento científico, desenvolvendo competências e habilidades inerentes à compreensão e interpretação de temas presentes na sociedade. O objetivo é formar cidadãos capazes de atuar, de forma ativa e transformadora, por meio de questionamentos e capacidade argumentativa para a tomada de decisões que envolvam contextos naturais, sociais e tecnológicos (BRASIL, 2018).

Zabala (1998) expõe que os conteúdos a serem trabalhados na escola devem potencializar os conhecimentos de forma que contribuam com uma formação integral e façam sentido para o estudante. Dessa forma, novos conhecimentos geram novas atitudes. Podem-se descrever os conteúdos factuais ou o conhecimento de fatos como acontecimentos, situações, dados; e os fenômenos como conhecimentos construídos ao longo da história da humanidade que devem ser memorizados e que serão integrados aos conceitos. $\mathrm{O}$ conteúdo conceitual passa a desenvolver a parte cognitiva do sujeito. $\mathrm{O}$ autor o caracteriza como descritivo e concreto. Afirma, ainda, que os conteúdos abordados pelo professor devem ter relevância para o estudante, a fim de poder ajudá-lo em situações e problemas reais. É o olhar para o que está além do texto que permite isso. Dessa forma, como Roth (2011) deixa implícito, a alfabetização científica fornece subsídios para que a população tenha capacidade de observar determinados problemas que estão presentes (embora nem sempre visíveis a um olhar menos atento) no cotidiano, e que seja possível elaborar respostas adequadas e específicas para cada problema.

De acordo com Zabala (1998), os conteúdos procedimentais são caracterizados por um conjunto de ações ordenadas e dirigidas para a realização de um objetivo. A partir dos conteúdos procedimentais, o sujeito é instigado a realizar ações que o encaminham para a construção dos conteúdos, sendo ele protagonista no processo de ensino e aprendizagem. É possível incluir nessas ações, regras, técnicas, métodos, habilidades, estratégias ou procedimentos para atingir uma ação específica. Um conteúdo procedimental é identificado por um verbo no infinitivo: ler, escrever, calcular, classificar, recortar, saltar etc. Logo, a realização de ações que formam os procedimentos é uma das condições para a aprendizagem.

Os conteúdos atitudinais, segundo Zabala (1998), estão diretamente ligados às atitudes, aos valores, às normas. As características diferenciadas da aprendizagem dos conteúdos atitudinais estão relacionadas com os componentes cognitivos, afetivos ou condutuais. Os conteúdos atitudinais potencializam o sujeito a pensar sobre a situação e os levam à tomada de decisão fundamentada e crítica sobre a sua realidade, ou seja, o letramento científico deve abranger quatro domínios indispensáveis para um indivíduo, sendo estes: o conhecimento, a atitude, a compreensão e a produção, e por último a capacidade. Todos se relacionam com a produção científica e tecnológica e com a capacidade de escrever, de ler e de interpretar os produtos produzidos pela ciência (ROTH, 2011).

O objetivo deste trabalho consiste em analisar uma proposta didática de um exercício com tema relacionado à saúde pública, de um livro utilizado no sétimo ano do Ensino Fundamental, de uma escola estadual do município de Campo Grande, Mato Grosso do Sul. Deseja-se saber se a atividade 
potencializa o trabalho do letramento científico, e também a capacidade de se apropriar do conhecimento científico, e tomar decisões, isto é, posicionar-se atitudinalmente e não apenas procedimentalmente para a tomada de decisão diante das situações da sociedade (ZABALA, 1998).

\section{Material e Métodos}

Para realizar a análise, o artigo aborda as perspectivas de Zabala (1998), que promove em suas discussões uma reflexão sobre os seguintes tipos de conteúdo: factual, conceitual, procedimental e atitudinal. Destacando os conteúdos como meio para uma aprendizagem significativa, não se restringindo apenas ao campo dos conceitos, mas ao domínio de fatos, capacidade de procedimentos e atitudes que devem ser integrados no processo escolar. A natureza do trabalho é de uma pesquisa baseada em análise documental. Em vista do que foi exposto, levantou-se a seguinte questão: a atividade proposta no livro didático do sétimo ano sobre saúde pública pode contribuir, significativamente, no processo de construção de conceitos, de procedimentos e de atitudes sobre o tema HPV?

O livro analisado neste trabalho, "Inovar: Ciências da Natureza" (LOPES; AUDINO, 2018), foi publicado em 2018 pela editora Saraiva, e tem como público-alvo o sétimo ano do Ensino Fundamental. A obra realizada pelos autores Sônia Lopes e Jorge Audino, também responsáveis pela editoração. É o segundo volume da obra, possui 248 páginas, sendo divididas em três unidades. A primeira unidade trata sobre conteúdos ligados à vida e evolução; a segunda parte aborda conteúdos relacionados à terra e ao universo e a terceira e última unidade trata de conteúdos ligados à matéria e à energia.

O material didático utilizado para a análise de conteúdos, na perspectiva de Zabala (1998), envolveu os seguintes critérios: 1) foi escolhido pelos professores de Ciências de uma escola da Rede Estadual de Educação do Estado de Mato Grosso do Sul, no município de Campo Grande, do $6^{\circ}$ ao $9^{\circ}$ ano do Ensino Fundamental; 2) os autores destacam a importância do letramento científico no Ensino Fundamental e na disciplina de Ciências da Natureza, com o intuito de formar cidadãos capazes de ler, de analisar e de interpretar as produções científicas nas áreas da tecnologia, social, natural e da saúde; 3) as páginas 74 a 87, na unidade I, capítulo 3, apresentam o tema e as atividades sobre políticas públicas de saúde e vacinação.

\section{Resultado e Discussão}

Observa-se na Figura 1 a proposta da atividade e, em seguida, procede-se uma análise dos conteúdos propostos. A experiência apresentada no livro traz conhecimentos que levam os estudantes a um processo de apropriação dos conceitos, desenvolvendo procedimentos para a aprendizagem e aplicação em atitudes presentes em suas realidades sociais.
Em outras palavras, a atividade proposta contribui para o letramento.

Figura 1 - Exercício proposto no livro didático de ciências da natureza, INOVAR

10. O condiloma acuminado é uma doença transmitida sexualmente e caracteriza-se por inúmeras verrugas na regiáo genital. A doença é causada pelo papilomavirus humano, conhecido como HPV.

- Observe os cartazes e, em grupo, pesquisem a respeito do HPV. Verifiquem se os postos de saúde da regiāo onde vocês vivem disponibilizam a vacina. Em seguida, com os demais colegas da turma e orientados pelo professor, promovam uma campanha na escola acerca da importância da vacina.

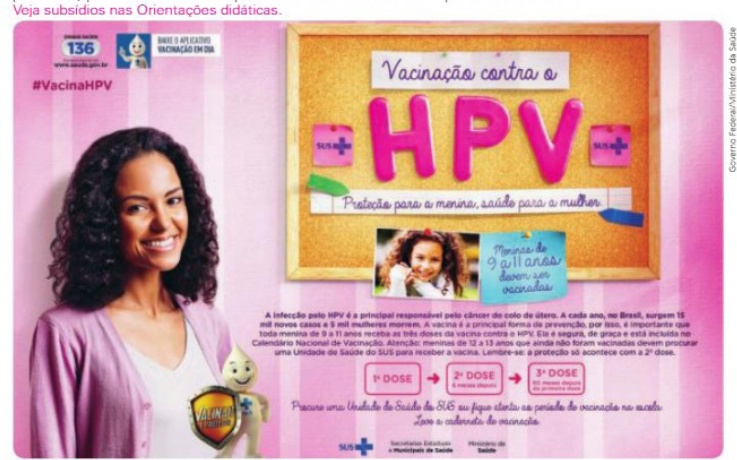

Fonte: Lopes e Audino (2018, p.84).

Para que o aluno compreenda o que é o vírus, é necessário realizar uma conceituação, como proposto na atividade. Assim, recorre-se ao Dicionário Online Brasileiro da Língua Portuguesa (MICHAELIS, s.d.), que disponibiliza seis significados para a palavra vírus. Dos seis significados, apenas um está relacionado com a Biologia; os demais significados estão relacionados com figuras de linguagem, obsoleto, informática ou a nenhuma área específica. O significado relacionado à Biologia é: "organismo infeccioso diminuto sem capacidade metabólica independente. São reprodutivos apenas no interior das células hospedeiras". A partir dessa definição de vírus se realizou um levantamento de outras conceituações apontadas na atividade, que retrata a vacinação do papilomavírus humano (HPV).

$\mathrm{O}$ HPV é um vírus pertencente à família Papillomaviridae, ao gênero Papillomavirus, possui forma icosaedrica e mais de oito mil pares de base de DNA dupla fita circular. Existem aproximadamente 150 subtipos de HPV que já foram completamente descritos, dos quais 100 ocasionam doenças em seres humanos. No genoma do HPV ocorrem mudanças constantes, em que as mutações ou a recombinação parecem ocorrer, frequentemente, no seu sequenciamento, semelhante ao que ocorre no genoma do indivíduo infectado (LETO et. al, 2011; NAKAGAWA; SCHIRMER; BARBIERI, 2010; OLIVEIRO JUNIOR et. al, 2016; SILVA et. al, 2016).

O HPV também é conhecido popularmente como crista de galo, figueira ou cavalo de crista, sendo o causador de tumores benignos e malignos de pele e mucosas. As pesquisas clínicas revelam que as doenças causadas pelo HPV podem ser lesões na pele (verrugas genitais), cânceres de colo do útero, vagina, vulva, pênis e ânus. O HPV também é responsável por causar tumores na parte interna da boca e na garganta (orofaringe), e pode ser benigno ou maligno (INCT, 2013; STEPHENS et. al., 2010).

De acordo com os conteúdos procedimentais destacados 
por Zabala (1998), que atuam no sentido de construir atividades cognitivas que permitem o sujeito analisar o processo de ação e os resultados que atinge, o cartaz apresenta situações significativas e funcionais, um meio que o conteúdo pode ser compreendido e utilizado, quando necessário. O capítulo específico não expõe o conceito de vírus e HPV, porém a atividade propõe procedimentos como pesquisa, exposição, produção de esquema e elaboração de materiais para serem divulgados no ambiente escolar.

Os conteúdos atitudinais estão diretamente ligados às atitudes e aos valores em relação ao conhecimento recebido, como descreve Zabala (1998). É possível identificar na proposta o componente afetivo, aquele que é determinante para conduzir a aprendizagem, pois apresenta um tema relevante para o público específico e guia para buscar informações sobre prevenção. São procedimentos indicativos de uma atitude de valorização da vida, da saúde, da produção e informação científica. Estes procedimentos serão realizados por meio de uma pesquisa proposta na atividade, em unidades de saúde próximas à escola e residências sobre a campanha de vacinação, estimulando a cooperação entre os alunos e a construção do conhecimento sobre o HPV. Dessa forma, o letramento se faz presente potencializando a tomada de decisão e os cuidados procedimentais no que diz respeito às relações íntimas.

O ensino sobre HPV na Educação Básica, de acordo com Pereira, Braga e Silva (2017), deve trabalhar conteúdos que envolvam a temática sobre Doenças Sexualmente Transmissíveis (DSTs) e algumas doenças de alto risco, como o HPV, principalmente, com adolescentes. Essa preocupação ocorre em função de danos que o vírus pode causar no organismo, propiciando o aparecimento de verrugas e doenças severas, como diversos tipos de cânceres, ou seja, o ensino sobre o que é o HPV deve acontecer com grupos de adolescentes e jovens, pois se enquadram em grupos de risco. Eles podem entrar em contato com o HPV durante o início da adolescência, e para impedir o contato/infecção precoce pelo vírus, o Ministério da Saúde criou uma campanha de vacinação contra o HPV por meio do Sistema Único de Saúde (SUS), atendendo meninas de 9 a 13 anos e meninos de 12 a 13 anos.

De acordo com Oliveira e Andrade (2016), o tema HPV é de grande importância. Esse deve ser divulgado e discutido nas escolas de Educação Básica, pois muitos alunos passam a ter contato com o tema nas salas de aula, quando o professor trabalha com a temática de DSTs. As aulas se tornam o momento oportuno para a divulgação dos métodos de prevenção, e um espaço para alertar sobre o sexo precoce na adolescência e sobre a importância da vacinação contra o vírus do HPV.

Com isso, na página 84 do livro foi possível destacar o desenvolvimento de uma atividade didática com intencionalidade investigativa, a partir de uma situaçãoproblema de cunho social, como a transmissão do HPV.
Essa atividade proposta pode levar o aluno a aprofundar os conteúdos conceituais, procedimentais e atitudinais, construindo conceitos científicos que são significativos em contexto, fornecendo possibilidades para a alfabetização e o letramento científico.

\section{Conclusão}

Este trabalho demonstra resultados importantes para entender como ocorre a alfabetização e o letramento científico, utilizando as perspectivas de Zabala como apoio para a análise do conteúdo. Ao realizar o levantamento bibliográfico sobre a alfabetização e o letramento científico se verifica como é importante que o professor seja letrado cientificamente em sua área de atuação, para que o mesmo consiga propor o desenvolvimento da alfabetização científica aos alunos. O processo de alfabetização até o letramento fornece ao aluno a capacidade não apenas de realizar a leitura sobre determinado assunto, mas também de interpretar e, mais importante, realizar uma observação crítica sobre o tema analisado e participar das discussões sobre os seus impactos na sociedade.

A escola de Educação Básica é o local adequado para realizar a construção e propagação do conhecimento científico, por meio de disciplinas que estejam ligadas à ciência. $\mathrm{O}$ professor será o responsável por realizar a alfabetização e letramento científico no âmbito escolar, principalmente, no Ensino Fundamental, no qual o aluno tem seu primeiro contato com a linguagem científica.

Essa análise confirma que a atividade oferece possibilidades reflexivas do conhecimento proposto no livro didático. Assim, a mesma não se limita aos conteúdos conceituais, mas objetiva a áreas sociais e culturais. Fica perceptível que tal proposta potencializa a refletividade e criticidade, desenvolvendo conceitos científicos que são significativos para os alunos do sétimo ano. Cabe acentuar que as ações como observar, anotar, pesquisar, ler, entre outras, foram identificadas na proposta e são de dimensão procedimental do conhecimento. No que se refere à dimensão conceitual, a partir da pesquisa foi proposta a investigação dos conteúdos de vírus, vacina, doenças sexualmente transmissíveis, HPV e prevenções. A contextualização proporciona a significação desses conceitos. A aproximação com caráter social envolvendo saúde e prevenção contribui para a tomada de decisões, ou seja, uma visão mais crítica a respeito da vacina. Desse modo, abordagens que implicam uma temática podem contribuir, significativamente, no processo de construção de conceitos, de procedimentos e de atitudes, possibilitando o letramento em saúde pública.

\section{Referências}

BRASIL. Ministério da Educação. Educação é a Base. Brasília, MEC, 2018.

INCT - Instituto Nacional de Ciência e Tecnologia das Doenças do Papilomavírus Humano. Guia do HPV - Entenda de vez 
os papilomavírus humanos, as doenças que causam e o que já possível fazer para evitá-los. São Paulo: CNPq, 2013.

LETO, M.G.P. et al. Infecção pelo papilomavírus humano: etiopatogenia, biologia molecular e manifestações clínicas. Anais Bras. Dermatol., v.86, p.306-317, 2011. doi: https://doi. org/10.1590/S0365-05962011000200014

LOPES, S.; AUDINO. J. Inovar: ciências da natureza. São Paulo: Saraiva, 2018.

MAMEDE, M.; ZIMMERMANN, E. Letramento científico e CTS na formação de professores para o ensino de Ciências. Enseñanza de las Ciências, p.1-4, 2005. Disponível em: https://ddd.uab.cat/ pub/edlc/edlc_a2005nEXTRA/edlc_a2005nEXTRAp320letcie. pdf

MICHAELIS. Dicionário On-line de Língua Portuguesa. Disponível em: <michaelis.uol.com.br/moderno-portugues/ busca/portugues-brasileiro/dicionário/> Acesso em: 20 out. 2020.

NAKAGAWA, J.T.T.; SCHIRMER, J.; BARBIERI, M. Vírus HPV e câncer de colo de útero. Rev. Bras. Enferm., v.63, n.2, p.307-311, 2010. doi: https://doi.org/10.1590/ S0034-71672010000200021

OLIVEIRA, L.M.P.; ANDRADE, V.A. Uma contribuição do ensino de ciências para a discussão e a prevenção do HPV no contexto do Programa de Educação de Jovens e Adultos. Rev. Práxis, v.8, n.15, p.119-134, 2016. doi: https://doi.org/10.25119/ praxis-8-15-683

OLIVERO JUNIOR, L. et al. Infecção por papilomavírus humano (hpv): aspectos gerais. Rev. Cient. Fac. Educ. Meio Amb., v.7, p.41-52, 2016. doi: https://doi.org/10.31072/rcf.v7i1.358

ROTH, D.M. Letramento científico: sentidos e valores. Rev. Notas Pesq., v.1, p.12-55, 2011. doi: https://doi.org/10.5902/ npesq.v0i0.3983

SANTOS, W.L. P. Educação científica na perspectiva de letramento como prática social: funções, princípios e desafios. Rev. Bras. Educ., v.12, p.474-492, 2007. doi: https://doi. org/10.1590/S1413-24782007000300007

SASSERON, L.H.; CARVALHO, M.P. Almejando a alfabetização científica no Ensino Fundamental: a proposição e a procura de indicadores do processo. Invest. Ensin. Ciênc., v.13, p.333-352, 2008.

SILVA, E.J. et al. Considerações relacionadas ao diagnóstico e tratamento do papilomavírus humano (HPV) em cavidade oral. Rev. Odontol. Univ. Cidade de São Paulo, v.28, n.2, p.117-125, 2016. doi: https://doi.org/10.26843/ro_unicid.v28i2.221

STEPHENS, P.R.S. et al. Virologia. In: MOLINARO. E.; CAPUTO. L.; AMENDOEIRA, R. (Org.). Conceitos e métodos para a formação de profissionais em laboratórios de saúde. Rio de Janeiro: EPSJV, 2010. p.125-220.

TEIXEIRA, F.M. Alfabetização científica: questões para reflexão. Ciênc. Educ., v.19, p.795-809, 2013. doi: https://doi.org/10.1590/ S1516-73132013000400002

ZABALA, A. A prática educativa. Como ensinar. Porto Alegre: ARTMED, 1998. 